\title{
Pharmacologic Opportunities for HIV Prevention
}

\author{
MR Nicol ${ }^{1}$ and ADM Kashuba ${ }^{1,2}$ \\ ${ }^{1}$ Division of Pharmacotherapy and Experimental Therapeutics, Eshelman School of Pharmacy, \\ University of North Carolina at Chapel Hill, Chapel Hill, North Carolina, USA \\ ${ }^{2}$ Clinical Pharmacology and Analytical Chemistry Core, Center for AIDS Research, University of \\ North Carolina at Chapel Hill, Chapel Hill, North Carolina, USA.
}

\begin{abstract}
Innovations in antiretroviral (ARV) treatment strategies have resulted in treated HIV-infected patients having life expectancies similar to those of uninfected individuals. Yet the number of individuals capable of HIV transmission is increasing - for every person in whom ARV treatment is initiated, four others are becoming newly infected with HIV. The limited progress with microbicides and vaccines for HIV prevention reinforce the need for a concentrated exploration of the utility of ARVs. Preliminary animal studies with topical and systemic ARVs show promising results. However, current clinical trials were designed without a comprehensive understanding of ARV pharmacokinetic-pharmacodynamic relationships in HIV prevention. This review focuses on current strategies for the prevention of HIV infection and on the ways in which the tools of pharmacology can be a valuable resource for determining pharmacodynamic targets, providing interspecies scaling of exposures, identifying the optimal drugs/drug combinations, doses, and dosing regimens, and designing efficient clinical trials.
\end{abstract}

Over the past 10 years, innovations in antiretroviral (ARV) treatment strategies have resulted in treated HIV-infected patients having similar life expectancies as their uninfected counterparts. ${ }^{1}$ Yet the number of individuals capable of HIV transmission is increasing. According to the Joint United Nations Programme on HIV/AIDS (UNAIDS), the number of newly infected individuals worldwide in 2008 was $~ 2.7$ million. $^{2}$ Since the early 1990 s, transmission rates have been relatively stable in the United States. ${ }^{3}$ This is attributable, in part, to increased efforts in carrying out HIV screening, placing patients into care, and promoting behavior-modifying interventions. ${ }^{4}$ However, countries that lack access to resources have not had similar success. For example, between 2001 and 2008, in the Middle East and North Africa, the number of newly infected individuals increased by $17 \%$, and the number of adult and child deaths caused by AIDS increased by $80 \% .^{2}$ The World Health Organization estimates that for every person in whom ARV treatment is initiated, four others are newly infected with HIV. ${ }^{5}$ Because current treatment interventions are not likely to curb the HIV epidemic, other prevention efforts are desperately needed.

As illustrated in Figure 1, interventions for HIV prevention can be divided into four main strategies based on the time course of exposure. In an individual who has yet to be exposed to HIV, behavioral and structural interventions may be effective. ${ }^{4}$ In an exposed individual at the time of coital exposure, a vaccine that provides neutralizing antibodies or a preexposure prophylaxis (PrEP) intervention with topical microbicides/ARVs or with systemic

(C) 2010 American Society for Clinical Pharmacology and Therapeutics

Correspondence: ADM Kashuba (akashuba@unc.edu).

CONFLICT OF INTEREST The authors declared no conflict of interest. 
ARVs may be effective. In an exposed individual shortly after the time of exposure, a vaccine or a postexposure prophylaxis (PEP) intervention with ARVs may be effective. Once infected, an individual may be rendered less infectious if placed on potent combination ARV therapy. 6,7

The efficacy of each of the aforementioned interventions depends on the type and timing of the intervention. Strategies that reduce transmission risks, such as male circumcision and condom use, along with other behavior-modifying interventions, have shown 50-80\% efficacy in clinical trials. ${ }^{8}$ However, achieving consistent implementation of these practices remains a challenge, particularly given the social and cultural conditions that can preclude women from being empowered to insist that their sexual partners adopt these measures. ${ }^{9}$ Recent advances in vaccine development are encouraging, ${ }^{10}$ but worldwide implementation of an effective vaccine is years away. Therefore, it is critical to identify potential pharmacologic interventions to curtail the HIV epidemic quickly.

These strategies include the use of microbicides and traditional ARV drugs, either systemically or topically. Typically, microbicides act in the vaginal lumen to either destroy the virus before it can traverse mucosal surfaces or prevent viral attachment to mucosal surfaces. This is in contrast to ARVs, which are distributed into tissues following oral or topical application and act at the mononuclear cellular level to prevent viral entry or replication. This article provides a brief review of the opportunities regarding pharmacologic interventions and their roles in the exposure continuum (Figure 1). We also summarize current obstacles facing the clinical pharmacology of HIV prevention and possible opportunities to overcome them.

\section{CURRENT APPROACHES TO PrEP AGAINST HIV INFECTION}

PrEP involves taking protective measures before an encounter that could lead to HIV infection. An effective PrEP intervention would be very valuable for sex workers, HIVnegative partners of HIV-seropositive individuals, and others who are at a high risk of being exposed to HIV. Both topical and systemic approaches to PrEP have been proposed. Although four topical microbicide compounds have been evaluated for efficacy, none has demonstrated protection in randomized placebo-controlled clinical studies. ${ }^{11}$ The first microbicide evaluated (Col-1492; a vaginal gel containing nonoxynol-9) unexpectedly demonstrated higher seroconversion rates (16\%) than placebo (12\%) in a phase III study involving 892 female sex workers in four countries. ${ }^{12}$ Four nonspecific microbicides (cellulose sulfate, Carraguard, Buffer Gel, and Pro 2000) have failed to demonstrate efficacy in clinical trials. ${ }^{11}$ Two additional agents, VivaGel (SPL7013 3\%; a membrane-binding inhibitor) and Amphora (Acidform lubricant; an acidifying vaginal-defense enhancer), are currently undergoing trials for safety and acceptability. A recent phase I study showed that when compared to placebo gel (hydroxyethyl cellulose), women who used the active drug were less adherent (77\% vs. $95 \%$ ) and reported they would be less likely to continue to use this product ( $36 \%$ vs. $61 \%)$.

With the disappointing results of microbicide trials, topical formulations of ARVs are actively being investigated. Nucleoside/tide analog and non-nucleoside analog reversetranscriptase inhibitors (NRTIs and NNRTIs) are of greatest interest because of their preintegration activity, long (intracellular) half-lives, safety profiles, and success in preventing infection in animal models. ${ }^{13,14}$ The attributes of the three leading candidate drugs are summarized here.

Tenofovir (TFV) is an NRTI that has advanced the furthest in PrEP clinical trials. It has been approved by the US Food and Drug Administration for HIV treatment since 2001 in the form of its salt, TFV disoproxil fumurate (TDF), and is often used along with the NRTI 
emtricitabine (FTC). Caprisa 004 was a phase II 24-month safety and efficacy study looking at coital-dependent use of $1 \%$ TFV gel in 900 high-risk South African women. Results of this randomized, double-blinded trial were announced in July 2010. When applied vaginally within $12 \mathrm{~h}$ before after sex, TFV gel demonstrated a $39 \%$ reduction in HIV infection. ${ }^{15}$

The efficacy of vaginally applied TFV $1 \%$ gel has been investigated in a macaque model of repeated low-dose exposure to a chimeric simian-human immunodeficiency virus $\left(\mathrm{SHIV}_{\mathrm{SF} 162 \mathrm{P} 3} ; 1050 \%\right.$ tissue culture infectious doses or $1.5 \times 10^{6}$ copies RNA per exposure). ${ }^{16}$ Three milliliters of TFV $1 \%$ gel, TFV $1 \%$ + FTC $5 \%$ combination gel, or placebo gel was administered vaginally $30 \mathrm{~min}$ before viral challenge in groups of six macaques. All six of the animals in the TFV and TFV + FTC gel groups remained protected from infection after 20 weekly viral challenges, whereas only one of the six animals in the placebo group remained uninfected $(P<0.001)$. The average plasma TVF concentrations from these protected animals $30 \mathrm{~min}$ after dosing were $16 \mathrm{ng} / \mathrm{ml}$ for TFV gel and $39 \mathrm{ng} / \mathrm{ml}$ for TFV + FTC gel. In comparison, preliminary pharmacokinetic data in humans after a 4-g intravaginal dose of $1 \%$ TFV gel demonstrate that blood plasma concentrations $>5 \mathrm{ng} / \mathrm{ml}$ are seldom achieved. ${ }^{17}$

Using male rhesus macaques, Cranage et al. demonstrated that rectal application of $3 \mathrm{ml}$ of TFV $1 \%$ gel up to 2 hours before exposure to simian immunodeficiency virus $\left(\mathrm{SIV}_{\text {mac251/32H }}, 20\right.$ median rectal infectious doses) prevented infection in six of nine animals, whereas only one in four of the animals in the placebo group remained uninfected. ${ }^{18}$ Analysis of plasma concentrations 15 min after dosing suggested that protection was associated with higher TFV exposures; the lowest plasma TFV concentration conferring protection was $120 \mathrm{ng} / \mathrm{ml}$. Currently, the TFV concentration in plasma achieved in humans after rectal application of TFV $1 \%$ gel is unknown. However, assuming that the average male rhesus monkey weighs $8 \mathrm{~kg}$ and an average human is $70 \mathrm{~kg}$, nearly $30 \mathrm{ml}$ of gel would need to be used in humans in order to achieve the same $\mathrm{mg} / \mathrm{kg}$ dose.

TFV has also been shown to be safe and efficacious in colorectal and cervical tissue explants. ${ }^{19,20}$ After a 1-h drug incubation, colorectal tissue demonstrated $100 \%$ protection from infection (2-h exposure to $30 \times$ the tissue culture $\mathrm{ID}_{50} \mathrm{HIV}_{\mathrm{BaL}}$ ) at concentrations of 10 and $100 \mu \mathrm{g} / \mathrm{ml}$ and $>90 \%$ inhibition at concentrations of 0.1 and $1 \mu \mathrm{g} / \mathrm{ml} .{ }^{19} \mathrm{In}$ a polarized cervical explant culture (in which only the epithelial layer is exposed to the air interface), the application of a 1-mg/ml TFV gel reduced p24 antigen concentrations from an $\mathrm{HIV}_{\mathrm{BaL}}$ inoculation by $1 \log$ as compared with untreated explants. ${ }^{20}$

UC871 is an NNRTI with an intracellular half-life of 5.5 days. ${ }^{21}$ This long half-life confers protection against HIV infection in explant culture models up to 6 days after initial drug exposure. ${ }^{21}$ In colorectal explants, complete protection from $\mathrm{HIV}_{\mathrm{BaL}}$ infection was seen at UC781 concentrations ranging from 10 to $100 \mu \mathrm{mol} / 1 .{ }^{19}$ In cervical explant tissue, 100 $\mu \mathrm{mol} / \mathrm{l} \mathrm{UC781}$ was able to confer complete protection from a 2-h exposure to $\mathrm{HIV}_{\mathrm{BaL}}$. At concentrations as low as $1 \mathrm{nmol} / \mathrm{l},>99 \%$ protection was seen. ${ }^{22}$ Using 20 pig-tailed macaques, and on the basis of in vitro toxicity assays, colposcopy examination, rectal lavage examinations, and measurements of rectal $\mathrm{pH}$ and rectal microflora, Patton et al. concluded that UC781 $0.1 \%$ and $1 \%$ gel formulations were safe as four daily doses of rectal $(2.5 \mathrm{ml})$ or vaginal $(1.5 \mathrm{ml})$ application. ${ }^{23}$ Even with repeated dosing, UC781 was not detected in the plasma of the animals, thereby suggesting minimal systemic absorption. Up to $6 \mathrm{~h}$ after administration of $1 \%$ gel, vaginal lavage samples contained UC781 concentrations above the half-maximal inhibitory concentration, but by $24 \mathrm{~h}$, they were undetectable. UC781 has completed phase I safety trials, and phase II trials for rectal and vaginal use are planned (http://www.conrad.org). 
Dapivirine (TMC120) is a second-generation NNRTI that maintains efficacy against many NNRTI-resistant strains of HIV. ${ }^{24}$ Although dapivirine's poor bioavailability precludes its use in oral dosing, its potential to achieve high local concentrations in a topical formulation may prove advantageous. In a cervical explant model, the absence of detectable proviral DNA with dapivirine exposure $\searrow 0.001 \mu \mathrm{mol} / \mathrm{l}$ demonstrated its potential efficacy in preventing HIV infection. ${ }^{25}$ At concentrations of 1-10 $\mu \mathrm{mol} / \mathrm{l}$, dapivirine demonstrated a

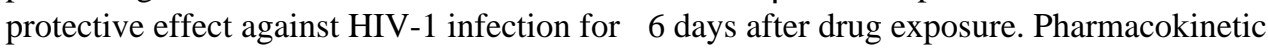
evaluations performed after 7 days of vaginally administered $\left[{ }^{14} \mathrm{C}\right]$ dapivirine $0.009 \%$ gel $(0.5 \mathrm{ml} /$ day in rabbits and $1 \mathrm{ml} /$ day in macaques) demonstrated low-to-undetectable plasma concentrations, with cervical and vaginal tissue concentrations being greater than the in vitro $\mathrm{EC}_{90}(0.9 \mathrm{ng} / \mathrm{ml})$ value for up to $48 \mathrm{~h}$ after dosing. ${ }^{26,27}$ Histopathological analyses of tissues from both species demonstrated that most of the drug remains on the mucosal surface, within the keratinized layer of the epithelium, or in compromised areas of tissue and rarely extends into the submucosa. Because compromised areas (lesions, ulcers, etc.) are often portals for HIV entry, this phenomenon could be clinically important. In two clinical studies, $2.5 \mathrm{ml}$ dapivirine gel concentrations of $0.001,0.002,0.005$, and $0.02 \%$ were administered twice daily for 42 days in healthy, HIV-negative women. ${ }^{28}$ Adherence was $>90 \%$ based on applicator count and, although sample timing in relation to gel application was not reported, mean (s.d.) concentrations in plasma on day 42 were 17.9 (15.2), 42.4 (29.0), 76.7 (58.3), and 427 (215) pg/ml, respectively. Dapivirine has also been developed into a vaginal ring delivery system; this controlled drug-release system and longer dwell time may have the advantage of facilitating better adherence to the regimen, thereby enabling more effective HIV prophylaxis. In a phase I study, two different intravaginal ring (IVR) delivery systems (matrix and reservoir) containing $25 \mathrm{mg}$ of dapivirine were evaluated for safety and pharmacokinetic exposure. ${ }^{27}$ The release of the drug varied greatly between the two rings. In the reservoir IVR, only $\sim 600 \mu \mathrm{g}$ was released over a 28 -day period as compared with $10.5 \mathrm{mg}$ released from the matrix IVR. Although the matrix IVR produced plasma concentrations 50-fold that of the reservoir IVR (maximum plasma concentration $\left(C_{\max }\right)$ 1,194 vs. $51.87 \mathrm{pg} / \mathrm{ml}$ ), both rings produced vaginal fluid concentrations above dapivirine's $\mathrm{EC}_{50}$ of $0.3 \mathrm{ng} / \mathrm{ml}$ for the entire 28 days of the study and for at least 5 days after removal $\left(C_{\max } 7.5-14.37 \mu \mathrm{g} / \mathrm{g}\right.$ for reservoir IVR and $850-1,900 \mu \mathrm{g} / \mathrm{g}$ for matrix IVR).

Although topical formulations of ARVs allow high local exposure while limiting systemic exposure, restrictions to their use may include: difficulty in application, problems with adherence to the regimen, lack of acceptance by user and partner, local irritation, and the necessity for multiple applications per encounter if multiple mucosal surfaces require protection. Systemic dosing of ARVs provides an alternative approach for protection and may overcome some of these challenges. Identifying an effective prophylactic pill that women can take outside the setting of sexual intercourse precludes the necessity to disclose such use to their partners, thereby empowering the women.

Currently, the target drug exposure required for preventing HIV infection at mucosal surfaces is unknown. Therefore, the current assumption is that higher drug exposures are better at conferring protection. However, ARVs differ greatly in their ability to penetrate mucosal tissues or secretions. ${ }^{29-33}$ Generally, highly protein-bound compounds do not gain access to these secondary compartments because of their affinity for plasma proteins such as albumin and $\mathrm{a}_{1}$-acid glycoprotein. Drugs such as the protease inhibitors, which are 95-99\% bound to plasma proteins, achieve female genital tract concentrations $<50 \%$ those in the plasma. ${ }^{32}$ In contrast, most NRTIs have a low degree of protein binding $(<0.7-49 \%)$ and achieve concentrations two-to sixfold higher in mucosal tissue than in plasma. ${ }^{32}$ However, protein binding is not the only predictor of ARV exposure. For example, maraviroc, a cellular entry inhibitor that demonstrates $85 \%$ plasma protein binding, has high penetration into cervicovaginal fluid (CVF) and vaginal tissue. After 7 days of dosing at $300 \mathrm{mg}$ of 
maraviroc twice daily, the areas under the concentration-time curve (AUCs) in CVF and vaginal tissue are 2.7 and 1.9 times higher, respectively, than that in plasma. ${ }^{30}$ Raltegravir, an integrase inhibitor that is $83 \%$ protein bound in plasma, has also been shown to penetrate well in the genital tract: the concentrations of the drug in CVF after multiple dosing are approximately equal to those in plasma. ${ }^{33}$ Currently, there are no published data regarding intrasubject pharmacokinetic variability in the female genital tract: there have been no studies sampling the same individuals under steady-state conditions over multiple days. However, the intersubject variability of drug exposure in the female genital tract is generally greater than in plasma (the coefficients of variation range $\sim 50-200 \%$ in CVF and 2-100\% in plasma).

An additional matter to be considered relating to ARV pharmacokinetics and pharmacodynamics at mucosal surfaces is protein binding within the mucosal secretions. The concentrations of albumin and $\mathrm{a}_{1}$-acid glycoprotein in CVF are $<1 \%$ of the values in plasma. ${ }^{34}$ Although the protein binding of drugs in genital secretions has not been extensively evaluated, maraviroc has recently been shown to have tenfold less protein binding in CVF than in plasma $(7.5 \%$ vs. $75 \%) .{ }^{30}$ This phenomenon must be considered in pharmacokinetic-pharmacodynamic analysis of ARV prevention strategies.

The extent of penetration of drugs into rectal tissues also has implications for HIV transmission. Exposures $\left(\mathrm{AUC}_{12} \mathrm{~h}\right.$ ) of maraviroc are $\sim 30$ times higher in rectal tissues than in plasma. ${ }^{31}$ Some drugs, such as the nucleoside/tide analogs, require cellular uptake and phosphorylation in order to be active against the reverse-transcriptase enzyme. Intracellular and extracellular concentrations of TFV and FTC have been recently evaluated in plasma and in cervical, vaginal, and rectal tissues after a single dose. ${ }^{35}$ Sampling was performed at time points from $24 \mathrm{~h}$ to 14 days after the dose. TFV exposures (as measured by $\mathrm{AUC}_{\text {day 1-14 }}$ ) were 5.8, 0.6, and 34 times higher in cervical, vaginal, and rectal tissues, respectively. FTC exposures were 41, 7, and 4.4 times higher in cervical, vaginal, and rectal tissues, respectively. Intracellular concentrations of TFV diphosphate were detected in all tissues for at least 7 days. FTC triphosphate was detected in tissues only for 2 days after dosing despite peripheral blood mononuclear cell concentrations persisting for 10 days. These initial tissue data suggest that these ARVs may be promising candidates for HIV prevention. However, more comprehensive pharmacokinetic data are required in order to guide drug development.

Several systemically dosed ARVs have been tested for PrEP efficacy in nonhuman primates and humanized mice. Oral dosing of CMPD167, a CCR5 inhibitor, prevented infection from vaginal exposures to $\mathrm{SHIV}_{162 \mathrm{P} 3}$ in $50 \%(10 / 20)$ of macaques when treatment with the drug was continued for 10 days after exposure and in $25 \%$ of the animals (one in a group of four animals) when the drug was given only for 4 days before exposure. ${ }^{36}$

Subbarao et al. demonstrated that with weekly exposure to low-dose SHIV $\left(3.8 \times 10^{5}\right.$ viral particles per exposure) in the rectum, oral daily $(n=4)$ or weekly $(n=4)$ doses of $22 \mathrm{mg} / \mathrm{kg}$ TDF can delay time to infection by $4.5-5.5$ weeks and provide a $60 \%$ lower per-exposure probability of infection. ${ }^{37}$ In this model, viral inoculation was performed $2 \mathrm{~h}$ after TFV administration: this time point was selected on the basis of pharmacokinetic sampling in a single macaque, which showed a concentration of $633 \mathrm{ng} / \mathrm{ml}$ at $2 \mathrm{~h}$ after the dose. Single samples of plasma in these macaques at $2 \mathrm{~h}$ after the dose revealed lower TFV exposures $(10-137 \mathrm{ng} / \mathrm{ml})$ in $80 \%$ of the macaques (four of the five animals tested) that were infected as compared with those that were protected (mean value 2,000 ng/ml). In 2008, GarciaLerma et al. evaluated five different routes, combinations, and/or schedules of TFV and FTC in a rectal, low-dose SHIV $\left(7.5 \times 10^{5}\right.$ viral particles per exposure $)$ repeat-exposure macaque model. ${ }^{38}$ Oral doses were selected on the basis of preliminary pharmacokinetic dose-ranging 
analyses in 11 animals ( 5 for TDF and 6 for FTC),demonstrating AUCs similar to those in humans at doses of 20-24 mg/kg of TDF and $20 \mathrm{mg} / \mathrm{kg}$ of FTC (AUCs for TFV were 3.2$3.4 \mu \mathrm{g} \cdot \mathrm{h} / \mathrm{ml}$, within the range related to humans, of $1.03-3.56 \mu \mathrm{g} \cdot \mathrm{h} / \mathrm{ml}$; AUC for FTC was $13.2 \mu \mathrm{g} \cdot \mathrm{h} / \mathrm{ml}$ in macaques and $\sim 10 \mu \mathrm{g} \cdot \mathrm{h} / \mathrm{ml}$ in humans; ref. 32). In this investigation, complete protection from HIV infection was achieved with daily subcutaneous dosing of TVF $22 \mathrm{mg} / \mathrm{kg}$ and FTC $20 \mathrm{mg} / \mathrm{kg}$. Other daily regimens (subcutaneous FTC $20 \mathrm{mg} / \mathrm{kg}$ alone or oral TDF $22 \mathrm{mg} / \mathrm{kg}+$ FTC $20 \mathrm{mg} / \mathrm{kg}$ ) achieved only partial protection (33 and $67 \%$, respectively).

Daily intraperitoneal doses of the combination of TDF + FTC $(5.2+3.5 \mathrm{mg})$ also proved to be protective in a humanized BLT mouse model. All five mice in the group were given FTC + TDF daily beginning 2 days before, and continuing for 7 days after, vaginal inoculation with $\sim 9 \times 10^{4}$ tissue culture infectious units of HIV-1 JRCSF. All remained infection-free, as compared with only one of the eight animals in the control group. ${ }^{39}$ This regimen was also tested in models of rectal and intravenous transmission of HIV. After intraperitoneal injections every day for 3 days, the animals were exposed to HIV- $1_{\text {JRCSF }}$ in the rectal mucosa or by intravenous injection while continuing to receive daily TDF + FTC for an additional 4 days. ${ }^{40}$ Under this regimen, no infections were noted with rectal challenge $(n=$ 9 ), and only one animal was infected with intravenous challenge $(n=9)$. As in macaques, pharmacologic data on these doses in mice are lacking. Calculated using weight-based scaling, intraperitoneal doses of $\sim 30 \mathrm{mg} / \mathrm{kg}$ were administered to these mice, which far exceeds the $\sim 4 \mathrm{mg} / \mathrm{kg}$ being used in current PrEP clinical trials.

Despite the sparseness of pharmacokinetic data from studies in humans and the pharmacologic limitations of the data from studies in animals, a number of clinical studies were initiated in multiple at-risk populations with standard dosing of TFV with or without FTC. Table 1 provides details of these PrEP investigations; the results from at least four of these investigations are expected to be released in 2010. Although all of these studies are using daily dosing in the investigation, this regimen may not be practical for individuals who are only occasionally exposed to high-risk encounters. In this situation, daily dosing may result in decreased rates of adherence to medication regimens (prophylaxis fatigue) and unnecessary systemic toxicity. Therefore, intermittent PrEP ( $\mathrm{PPrEP}$ ), using dosing either related or unrelated to the occurrence of coitus, is also being investigated.

Several ARVs have pharmacokinetic profiles that are favorable for $i$ PrEP. The pharmacokinetics of maraviroc, TFV, and FTC have been discussed in detail previously. Maraviroc also has a long residence time in the genital tract, remaining at levels higher than the protein-free half-maximal inhibitory concentration in CVF for at least $72 \mathrm{~h}$ after a dose. ${ }^{30}$ TFV and FTC also have extended pharmacokinetic profiles in mucosal surfaces after a single dose. ${ }^{29,32}$ An analysis of blood and rectal cells in macaques after oral TDF + FTC $(20+22 \mathrm{mg} / \mathrm{kg})$ revealed long intracellular half-lives for TFV diphosphate $(78-170 \mathrm{~h})$ and FTC triphosphate (15-49 h). ${ }^{41}$ Interestingly, despite the presence of TFV diphosphate in rectal mononuclear cells at $2 \mathrm{~h}$ after the dose, FTC triphosphate was not detected until $24 \mathrm{~h}$ after the dose. The explanation for this finding is still under investigation.

With the use of these drugs, $ı$ PrEP has shown positive results in some investigations in animals. For example, all six of the macaques that were treated with subcutaneous TFV + FTC $(22 / 20 \mathrm{mg} / \mathrm{kg}) 2 \mathrm{~h}$ before and $24 \mathrm{~h}$ after repeated low-dose SHIV exposures in the rectum were protected from infection for $>14$ weeks. ${ }^{38}$ A recent investigation has demonstrated maximum protection from 14 weekly SHIV exposures when a subcutaneous pre-exposure dose $22 \mathrm{~h}$ before exposure is followed by a postexposure dose at $2 \mathrm{~h}$ after the exposure (hazard ratio 16.7) (ref. 41). This protection decreases when the pre-exposure dose is administered as early as 3 and 7 days before infection (hazard ratio 15.4 and 9.3, 
respectively) or if the postexposure dose is delayed by 22 or $26 \mathrm{~h}$ after the infection (hazard ratio 4.1 and 4 , respectively).

Before a clinical trial for $\mathrm{IPEP}$ can be performed, thorough extracellular and intracellular pharmacokinetic analyses must be performed with these agents to allow optimal interspecies scaling from humanized mice, to macaques, to humans. Although it is not known whether the pharmacokinetic-pharmacodynamic relationship with ARVs and HIV prevention is similar among these species, it would be useful to assure at least similar ARV exposures. HPTN 066 is a multisite phase I study scheduled to begin in 2010. This study will involve four different treatment regimens in HIV-negative men and women (arm 1: $300 \mathrm{mg}$ TDF/ $200 \mathrm{mg}$ FTC weekly; arm 2: $300 \mathrm{mg}$ TDF/200 mg FTC twice weekly; arm 3: $600 \mathrm{mg}$ TDF/ $400 \mathrm{mg}$ FTC twice weekly; and arm 4: $300 \mathrm{mg}$ TDF/200 mg FTC daily). Sampling of rectal, seminal, and vaginal fluids, plasma, cells, and tissues will be performed to assess the doseproportionality of intracellular phosphorylated metabolites of TFV and FTC and to quantify their intraindividual variability. The information from this study will fill a large gap in the knowledge of intracellular kinetics of these medications at multiple mucosal surfaces and will help identify the time periods during which specific dosing strategies confer protection. Quantification of the intraindividual variability will enable future studies to use drug concentrations as a determinant of adherence to medication regimens.

Finally, a preliminary clinical study in Kenya and Uganda is currently under way among 150 serodiscordant couples to evaluate the safety and acceptability of $\mathrm{PPEP}$ (http://

www.iavi.org). In this investigation, subjects will take standard doses of oral TDF/FTC once daily or intermittently (defined as twice weekly plus coitus-related dosing). Samples for blood plasma and intracellular concentrations will be obtained.

\section{CURRENT APPROACHES TO PEP}

PEP involves prevention of HIV infection after a known or suspected exposure in a healthcare worker (occupational PEP) or a sexual encounter associated with risk of infection (nonoccupational PEP; nPEP). Guidelines and recommendations for occupational and nPEP come from small studies, case reports, and data from animal studies. Adequately powered interventional clinical trials are prohibitively expensive, given the low HIV-infection rates and the need for an active control arm. Current Centers for Disease Control and Prevention guidelines (updated in 2005—http://www.cdc.gov/hiv/resources/guidelines/index.htm) for occupational PEP use an algorithm based on type of exposure and the infection status of the source. Although dual or triple combination therapy is superior to monotherapy for the treatment of HIV infection, there is no evidence that this superiority holds true for PEP. However, on the basis of data from animal studies, 4 weeks of therapy is recommended. ${ }^{42}$ The selection of a regimen is largely empirical and based on potency and durability data from treatment studies. Preferred regimens involve one or two nucleoside analogs (zidovudine: ZDV, lamivudine: 3TC, FTC, or TDF) with a protease inhibitor (lopinavir/ ritonavir) or efavirenz.

One case-control study investigating seroconversions of health-care workers after needlestick injury demonstrated that, after controlling for other factors (e.g., deep injury, visible blood on the needle, and terminal illness of the source) the use of ZDV reduced the risk of infection by $81 \%$ (adjusted odds ratio $=0.21, P=0.002$ ) (ref. 43). This provides important proof of concept for utilizing ARVs in a PEP setting.

Nonoccupational exposures include those that involve the male and female genital tracts, the rectal mucosa, and exposure from intravenous drug use. Historically, the use of nPEP has been less consistent than occupational PEP because the benefit of the routine use of the former has been debated. One major concern is behavioral disinhibition. The potential for 
increase in risky behaviors with increased availability of nPEP has been both supported and refuted in observational studies. ${ }^{29}$ However, studies and case reports have supported the feasibility of nPEP, ${ }^{29}$ and, in 2005, the Centers for Disease Control and Prevention issued recommendations for its use (http://www.cdc.gov/hiv/resources/guidelines/index.htm). For reasons similar to those that apply to PEP studies, an adequately powered interventional study for nPEP is unlikely to be performed. Given that there is no evidence that one particular group of drugs is more effective than others, selection is based on patient-specific issues and prescriber experience. Preferred regimens include two nucleoside analogs (3TC or FTC with ZDV or TDF) with lopinavir/ritonavir or efavirenz.

The timing of initiation of prophylaxis is critical to nPEP. From the timeline of mucosal infection developed from animal and in vitro models (Figure 2), a 24-h window of protection may be optimal for intervention. The Centers for Disease Control and Prevention recommendation of 28 days of treatment initiated within $72 \mathrm{~h}$ of exposure is supported by studies in animals. Maximum protection from infection in macaques given high-dose subcutaneous TFV ( $30 \mathrm{mg} / \mathrm{kg} /$ day) is obtained when treatment is initiated within $24 \mathrm{~h}$ of exposure and continued for 28 days. ${ }^{42}$ Delaying treatment by 48 or $72 \mathrm{~h}$ after exposure and then continuing treatment for 28 days was $<20 \%$ effective at protection. If treatment was started within $24 \mathrm{~h}$ but stopped after 10 days, the treatment was only $50 \%$ effective. If treatment was started within $24 \mathrm{~h}$ and stopped after 3 days, the treatment was completely ineffective.

\section{CURRENT APPROACHES TO TREATMENT OF THE INDEX CASE}

The model for sustaining an epidemic has been applied to HIV infection. ${ }^{44}$ The requirements to sustain an epidemic are summarized in the mathematical equation $R_{0}=$ $\beta \Delta C . R_{0}$ is defined as the number of secondary individuals infected by a single infected person. $\beta$ is the transmission probability per exposure (including the size/concentration of the inoculum), $\Delta$ is the length of time an individual remains infected, and $C$ is the rate at which the infected individual acquires new partners. According to this model, $R_{0}$ must be $>1$ for the HIV epidemic to be maintained. In the absence of a cure for HIV, there is little that can affect $\Delta$. Although behavioral interventions and education have influenced $C$ to a degree, $\beta$ remains the main target that can be manipulated to control the HIV epidemic. Chakraborty et al. developed a model of sexual transmission in which a logarithmic increase in the probability of male-to-female HIV transmission occurs with increasing concentrations of HIV RNA in the semen and numbers of receptors in the cervical tissue. ${ }^{45}$ These mathematical formulas help to highlight the potential public health benefit of suppressing HIV transmission by treating HIV infection. Although local suppression of viral replication is paramount to reducing infectivity, ${ }^{6}$ there is no known threshold of HIV RNA concentration below which a person can be rendered noninfectious. Observational and prospective studies have suggested that the threshold HIV RNA concentration in blood could be $<3,500 \mathrm{copies} / \mathrm{ml}$ (ref. 6). However, similar data for the genital tract are lacking, largely because of limitations in sample collection and insufficiently sensitive HIV RNA detection methods. Assays that are able to detect low viral copy numbers require large sample volumes of genital secretions, often much higher than what is feasible to collect.

Observational studies have demonstrated the ability of ARV therapy to reduce HIV transmission. A study in Uganda demonstrated that initiation of ARV therapy (drugs not specified) along with counseling could reduce risk of transmission by $\$ 9 \%$ over 2 years. ${ }^{46}$ A 6-year study in Rwanda and Zambia involving 2,993 serodiscordant couples observed only four new infections in the partners of those receiving ARV therapy and 171 infections in couples that were not treated (odds ratio $0.87,95 \%$ confidence interval 0.79-0.96; ref. 47). 
Mathematical models have also been developed to predict the role of ARV therapy in reducing transmission. ${ }^{6}$ These models vary in their predictions depending on the assumptions regarding the number needed to be treated, the infectivity of the HIV-positive individuals, and the ability of ARVs to suppress HIV RNA. Although some of these models suggest that widespread use of preventive ARV therapy would curb the epidemic, others are of the opinion that, given the likely sexual disinhibition and increase in HIV resistance as a result of such preventive therapy, any benefit would be negated. ${ }^{6}$ Acutely infected individuals have high viral shedding from the genital tract, often before HIV RNA is detected in blood. Given that these individuals may be responsible for a significant proportion of new HIV infections, targeting this cohort for early testing and treatment may make an important contribution to public health.

The optimal choice of ARVs for "sterilization" of the genital tract has yet to be determined. Drug exposure in the female genital tract is reviewed elsewhere in this article (see "Current Approaches to PrEP of HIV Infection"). As is the case in the female genital tract, there is differential penetration of ARVs in the male genital tract as well. ${ }^{29,31,48-51}$ Nucleoside analogs (abacavir: ABC, ZDV, TDF, and 3TC) achieve exposures in semen ranging from 150 to $600 \%$ of those observed in blood plasma. ${ }^{29}$ After oral administration of TDF, intracellular mononuclear TVF-DP concentrations in the semen are at least eight times higher than in peripheral blood mononuclear cells. ${ }^{48}$ However, this increased extracellularintracellular relationship with respect to concentration levels in semen does not hold for ZDV or 3TC. Despite four- to sixfold higher concentrations in seminal plasma, intracellular mononuclear cell concentrations of ZDV-TP in semen are $40 \%$ of those in peripheral blood mononuclear cells, and mononuclear cell concentrations of 3TC-TP in semen are approximately equal to those in peripheral blood mononuclear cells. ${ }^{51}$ As in the female genital tract, there are no data regarding intrasubject pharmacokinetic variability in the male genital tract. However, intersubject variability in drug exposure is generally greater in the male genital tract (the coefficients of variation range from 100 to 300\%) than in blood plasma. These data illustrate the importance of quantifying intracellular drug exposure to develop accurate pharmacokinetic-pharmacodynamic models of HIV prevention.

The pharmacokinetics of newer classes of ARVs have recently been evaluated in semen. The AUC of maraviroc in semen is $40 \%$ lower than in blood plasma. However, similar to findings in the female genital tract, low protein binding in semen results in free drug concentrations 28 -fold higher than the protein-free $90 \%$ inhibitory concentration. ${ }^{31}$ Raltegravir concentrations are 3-6 times higher in semen than in blood plasma; ${ }^{49}$ however, the protein binding in seminal plasma has not been determined. A summary of ARV exposure in relevant mucosal fluids and tissues is presented in Table 2.

An important consideration for choosing ARVs for HIV prevention is genital tract compartmentalization. Genotypic differences have been found in HIV isolated from blood plasma and the male and female genital tracts, and this constitutes evidence of viral compartmentalization. ${ }^{52,53}$ These resistance patterns coincide with observed ARV drug exposure in genital secretions. For example, protease inhibitors have the poorest penetration into the genital tract. This may explain the presence of protease-resistant viral isolates in seminal plasma and vaginal fluid. ${ }^{29}$ Likewise, an increased number of mutations conferring resistance to NNRTIs have been detected in the genital tracts of treatment-experienced women: for instance, $<1 \%$ of the efavirenz (an NNRTI) exposure observed in blood plasma is achieved in CVF. ${ }^{32}$ Although not adequately tested, it is assumed that ARVs with a higher exposure in the genital tract will be more effective at reducing viral loads in the genital compartments. Understanding drug penetration into the genital tract will allow for educated choices for therapy aimed at "sterilizing" the tract. ${ }^{7}$ 
In January 2008, an international debate followed the release of a consensus statement by Swiss HIV experts declaring that an HIV-infected person on effective ARV therapy (defined as suppressed viremia for $\ 6$ months) with no other sexually transmitted infections may be considered noninfectious. The statement sparked much concern because of its implications with respect to behavioral practices of HIV-infected individuals. A model-based analysis of transmission risk per exposure type demonstrated that, although the risk of transmission in the setting of effective treatment was decreased, it was not nonexistent and that risky behaviors should be discouraged ${ }^{54}$ HPTN 052 is the first prospective trial designed to evaluate the use of ARVs in reducing HIV transmission (http://www.hptn.org). This phase III, two-arm, international study will compare the infection rates related to two different treatment strategies in serodiscordant couples. This trial is currently enrolling couples in which the infected partner begins ARV therapy (with a recommended regimen of 3TC + ZDV + efavirenz or atazanavir) either immediately or when he/she has two consecutive $\mathrm{CD}^{+}$cell counts below $250 \mathrm{~mm}^{3}$, or develops an AIDS-defining illness. Approximately 1,750 couples are being followed for 60 months, and the results are expected in 2013.

\section{DEVELOPMENTAL OBSTACLES IN HIV PREVENTION STUDIES}

All current clinical trials for HIV prevention are evaluating TDF, alone or in combination with FTC. These were chosen on the basis of safety, availability, and preliminary data from nonhuman primates. Because preclinical pharmacology was not prospectively or concomitantly performed for the effective subcutaneous doses ranging from 22 to $30 \mathrm{mg} / \mathrm{kg}$ in macaques, standard, labeled treatment dosing strategies were pursued for the clinical studies. This approach has a number of limitations in HIV prevention research, and more data are required to make rational choices for drugs, doses, and dosing strategies.

Quantifying the pharmacokinetics of ARVs in mucosal tissues is complex. Concentrations of the drugs in blood plasma do not always correlate with those in the genital tract and rectum, and accumulation ratios vary between and within therapeutic classes..$^{29,31,32}$ The mechanisms that underlie these differences have yet to be fully elucidated. In the male genital tract, the primary influence appears to be protein binding. However, as illustrated in Figure 3, this is not the case for the female genital tract. Further investigations on the physicochemical properties of ARVs that are associated with increased mucosal penetration are required.

Although the majority of ARVs act intracellularly, only the NRTIs require further phosphorylation in order to exert antiviral activity. Limitations in analytical chemistry detection technology and tissue or cell sampling logistics have precluded quantification of these active metabolites in the female genital tract. In view of the fact that an extracellularintracellular disconnect with respect to ZDV, 3TC, and TFV has been found between semen and blood, ${ }^{48,51}$ quantifying these exposures in the female genital tract will be important for identifying appropriate concentration targets for HIV prevention. Further, quantification of the intersubject variability in subpopulations of mononuclear cells susceptible to HIV infection may also provide insight into the probability of protection in a targeted population. Finally, additional insight is required into the part(s) of the female genital tract (i.e., vagina, cervix, or uterus) that may be most susceptible to HIV infection and the part(s) that can serve as a pharmacologic and virologic surrogate for the others. Advanced physiology-based modeling may be able to assist in this effort.

Developing a reliable animal model for prevention studies has been a challenging task. HIV infection is a species-specific disease, and this limits the flexibility afforded by animal models. For decades, research has been limited to macaque models, which permit the study of SIV, a virus similar to, but not identical with, HIV. SIV's distinct characteristic with 
respect to co-receptor usage can confound the results of prevention studies. ${ }^{55} \mathrm{SIV}_{\text {mac }}$ and $\mathrm{SIV}_{\mathrm{mc}}$ most closely resemble HIV-1 in progression of plasma RNA and CD4 T-cell response. $^{7}$ The chimeric SHIV, although containing a portion of the HIV-1 genome, does not mimic the progression of infection as closely as SIV does. Some models utilize progesterone therapy to thin the epithelial layer of the vaginal tract, increase the probability of infection, and increase the likelihood of documenting an ARV effect. However, the impact of this intervention on ARV concentrations or efficacy in these tissues is unknown. Finally, exposure models also differ. The low-dose repeat-exposure model was developed to mimic the human condition. The single high-dose exposure model represents the "worst case scenario." However, one investigation using oral TDF ( $22 \mathrm{mg} / \mathrm{kg}$ ) for PrEP found less protection with the low-dose exposure model (40\%) than with the high-dose model (75\%). ${ }^{56}$ The variability between these models is a strong consideration for assessing outcomes.

Interspecies scaling of ARV exposures between macaques and humans has been difficult given the limited amount of pharmacokinetic information generated in these studies. The only systemic ARV regimens that have demonstrated full protection against rectal, vaginal, and oral exposure to SHIV in macaques are daily or intermittent subcutaneous administration of $22 \mathrm{mg} / \mathrm{kg}$ TFV or $22 \mathrm{mg} / \mathrm{kg}$ TFV $+20 \mathrm{mg} / \mathrm{kg}$ FTC. ${ }^{13,38}$ Although no $C_{\max }$ or AUC value was reported for subcutaneous TFV, the $C_{\max }$ of the selected humanequivalent oral dose $(633 \mathrm{ng} / \mathrm{ml})^{37}$ was approximately twice as high as the observed $C_{\max }$ in humans. ${ }^{32}$ Local exposure of ARVs in mucosal tissues after topical administration remains to be measured comprehensively in animal models. Given the smaller genital and rectal cavities of macaques, it is possible that animals in the preclinical trials discussed above received supratherapeutic dosing.

The humanized mouse model has recently been developed to overcome some of the logistical challenges associated with macaque models. The first humanized mouse was from a severe combined immunodeficiency (SCID) variant. The mutation in the prkdc gene leading to loss of function in mature $\mathrm{T}$ and $\mathrm{B}$ lymphocytes allows these mice to be infected with foreign tissue without rejection. ${ }^{14}$ Because only the implanted tissues can be infected with HIV, this has limited applications for HIV prevention research. The SCID-hu peripheral blood lymphocyte model was developed by intraperitoneal injection of human peripheral blood lymphocytes. Although populations of human B and T cells can be recovered, the repertoire is limited and transient, with no renewal capacity. These mice have been used for studying viral pathogenesis and screen vaccine candidates. However, the limited numbers of human cells in mucosal tissues make them poor candidates for prevention research. In the SCID-hu Thy/Liv model, human thymus and liver are grafted into the SCID mouse, with subsequent production of human mononuclear cells (including $\mathrm{CD} 4^{+}$cells). However, this model is not susceptible to mucosal transmission of HIV, given that the $\mathrm{T}$ cells appear to be confined mostly to the area of the thymus. More recent models such as the Rag2 ${ }^{-/-}$IL2R $\gamma \mathrm{c}^{-/-}$, the NOD/SCID-IL2R $\gamma^{-/-}$, and the NOD/SCID BLT mice generally have more extensive humanization of mucosal tissues. Rag $2^{-/-} \mathrm{IL} 2 \mathrm{R} \gamma \mathrm{c}^{-/-}$mice are developed by intrahepatic placement of human CD34 ${ }^{+}$hematopoietic stem cells, which then differentiate into human B, T, and dendritic cells. These mice are susceptible to HIV after systemic, vaginal, or rectal exposure. Additionally, appropriate viral suppression and $\mathrm{CD} 4^{+} \mathrm{T}$-cell recovery can be achieved by administering ARV therapy. ${ }^{57}$ The NOD/SCID$\mathrm{IL} 2 \mathrm{R} \gamma \mathrm{c}^{-/-}$mice are generated by the introduction of $\mathrm{CD} 34^{+}$hematopoietic stem cells, either intrahepatically or intravenously. This model is currently undergoing investigations regarding its susceptibility to mucosal transmission of HIV. In the NOD/SCID BLT mouse, human fetal liver and human fetal thymus are implanted under the kidney capsule of the NOD/SCID mouse, with subsequent transplantation of human fetal liver CD34 ${ }^{+}$ hematopoietic stem cells. This model has shown a robust humanization of the rectal and 
female genital tracts and susceptibility to both vaginal and rectal HIV transmission. ${ }^{14}$ However, no pharmacokinetic investigations have been performed in this model.

An alternative, or complementary, approach to a preclinical animal model for HIV prevention strategies is the tissue explant culture model. This technique has been previously used with human thymus tissue and has more recently been applied in rectal, vaginal, and cervical tissues, which are the common sites of exposure in HIV transmission. ${ }^{58}$ This promising ex vivo approach allows human tissue from healthy volunteers to be used in the study of HIV transmission as well as ARV safety, efficacy, and pharmacology. Insights into successful prevention strategies may be obtained by varying drug doses, viral isolates, and titers in this model. This technique has been utilized to evaluate several candidate microbicides. ${ }^{19,20,22,25}$

\section{FUTURE ROLE OF CLINICAL PHARMACOLOGY IN BRIDGING THE GAPS}

As more predictive preclinical models are developed for prevention, the tools of pharmacology will become a valuable resource for determining pharmacodynamic targets, providing interspecies scaling of exposures, identifying the optimal drugs/drug combinations, doses, and dosing regimens, and designing efficient clinical trials.

Characterization of the pharmacokinetics occurring at mucosal surfaces that are prone to infection (rectal, vaginal, and cervical) has provided valuable information about the ARVs that should be further investigated in prevention trials. The drugs that accumulate in tissues (e.g., TFV, FTC, 3TC, and maraviroc), as well as those that achieve concentrations above their respective $90 \%$ inhibitory concentration values (e.g., raltegravir, atazanavir, and darunavir) are candidates for further investigation. However, the specific pharmacokinetic behavior of these drugs in tissues, including residence times, cellular uptake, and intracellular phosphorylation, remains unknown. Although it is known that certain physiochemical properties such as protein binding, lipophilicity, and molecule size have an impact on the drug's penetration into genital tract secretions, the mechanisms of uptake remain undefined, particularly for the female genital tract. Even without a complete mechanistic understanding of drug movement between these compartments, pharmacokinetic modeling may still allow for accurate estimation of concentrations in the genital tract.

The recent results from the Caprisa 004 trial demonstrate the importance of incorporating robust pharmacology sampling into future prevention trials. Using CVF concentrations, a compelling trend was established between higher TNF CVF concentration and lower HIV infection rates. A similar trend was noted with lower HSV2 infection rates, Particularly when concentrations were higher than the TNF in vitro $\mathrm{IC}_{50}$ for $\mathrm{HSV} 2$ of approximately $10,000 \mu \mathrm{g} / \mathrm{ml} .{ }^{59}$ Based on these data, it's clear that including detailed pharmacokinetic samping at the site of infection in HIV prevention trails will allow for the determination of pharmacologic targets for protection.

It is critical to determine the concentration of ARVs needed at the site of exposure to prevent HIV infection. Preclinical models have shown that ARVs can protect against HIV infection. However, in the absence of rigorous pharmacokinetic data, it is difficult to determine how these results can be extrapolated to humans. More focused, well-designed sampling strategies in preclinical models can provide a great deal of information with only minimal increase in cost and effort. The tissue explant culture model may also assist in defining pharmacokinetic-pharmacodynamic relationships in cervical, vaginal, and rectal mucosal tissues. Physiology-based modeling may then assist in selecting the most appropriate drugs or combinations, doses, and dosing strategies to move forward in clinical investigations. 
Once drug targets for prevention are identified, determining the appropriate surrogate sampling schemes for generating data in large groups of individuals will be required. Figure 4 represents the compartments from which pharmacokinetic data can be obtained. It is possible that only intracellular ARV concentrations from a specific cellular subset in tissues predict efficacy. However, in order to expediently perform larger population pharmacokinetic-pharmacodynamic modeling analysis from registered clinical trials, surrogates for this exposure will need to be developed. However, optimal use of these surrogates requires accurate information related to the time points at which the interventions are used. Without proper dose-timing information, any drug exposure measure will have little value as a tool for assessing adherence to dosing regimens.

Likewise, when comparing local exposures in the mucosal tissues to blood plasma concentrations, single paired concentrations will not yield as comprehensive an understanding of drug exposure as AUC measurements. In order to calculate an AUC, however, one requires either extensive intraindividual sampling or pharmacokinetic models with population pharmacokinetic approaches. This is why many of the clinical trials conducted to date have not prospectively incorporated this degree of pharmacokinetic sampling. Future studies with a more considered approach to obtaining pharmacokinetic data will provide additional insight into the pharmacologic relationships among dose, drug concentrations in plasma, drug concentrations in mucosa, and the efficacy of the treatment.

Finally, an important consideration in analyzing clinical trial data is the confounder of adherence to therapy. In the case of prevention research, reliance is placed on the individual subjects to ensure adherence to the therapeutic regimen. In order to adequately interpret clinical trial outcomes, investigators require a thorough understanding of the number of subjects in the active treatment arm who are not taking their medications, and the number of subjects in the placebo arm who are being exposed to the drug (e.g., as a result of drug pooling/sharing). Having too many of these subjects in each group has the potential to confound the results and negate the time and resources invested in the clinical trial. Realtime pharmacokinetic sampling with subsequent adherence interventions could be built into these investigations for pharmacologic quality assurance. HPTN 066 is the first study designed specifically to build a pharmacokinetic model to address this issue in subsequent prevention studies.

\section{CONCLUSION}

The recent failures with microbicide and vaccine candidates for HIV prevention necessitate a focus on topical and systemic ARV therapy. Implementation of an acceptable and efficacious ARV prevention strategy will dramatically affect the global HIV epidemic and significantly reduce the burden of disease. Both topical and systemic use of ARVs in animal models have produced promising data. From these data, a number of prevention studies were created to investigate a limited range of ARVs in a variety of populations and geographic settings (as of this year, nearly 20,000 individuals will be enrolled in PrEP trials). Because these current clinical trials were not designed to provide definitive information to correlate drug exposure with HIV protection, many pharmacologic opportunities still exist. The target ARV exposure for prevention of infection in animals or tissues is unknown, as is the effect of combining ARVs from different drug classes. New analytical capabilities and novel sampling strategies allow cellular pharmacokinetics and dynamics to be more diligently investigated and to identify surrogate markers for protection. Assessing the proportionality between intracellular and mucosal tissue concentrations of drugs will allow the development of predictive pharmacokinetic-pharmacodynamic models to investigate strategies for intermittent PrEP at suitable dosages that are most likely to succeed. Standardization of realtime drug adherence/exposure measures in clinical studies will ensure interpretable results 
once studies are complete. The tools, techniques, and expertise of clinical pharmacology are essential to advancing the field of HIV prevention and will continue to play a significant role until the HIV epidemic can be contained.

\section{Acknowledgments}

M.R.N. is a Rho Chi-APFE First-Year Graduate Scholar. A.D.M.K. is director of the UNC Center for AIDS Research: Clinical Pharmacology and Analytical Chemistry Core (P30A150410) and is supported in part by R34AI87065.

\section{References}

1. Van Sighem, A.; Gras, L.; Reiss, P.; Brinkman, K.; de Wolf, F. Life expectancy of recently diagnosed asymptomatic HIV-infected patients approaches that of uninfected individuals. 17th Conference on Retroviruses and Opportunistic Infections; San Francisco, CA. 16-19 February 2010;

2. UNAIDS. AIDS Epidemic Update 2009. Nov. 2009 http://www.unaids.org/en/KnowledgeCentre/ HIVData/EpiUpdate/EpiUpdArchive/2009/default.asp

3. CDC. HIV Transmission Rates in the United States. Dec. 2008 http://cdc.gov/hiv/topics/ surveillance/resources/factsheets/transmission.htm

4. Coates TJ, Richter L, Caceres C. Behavioural strategies to reduce HIV transmission: how to make them work better. Lancet. 2008; 372:669-684. [PubMed: 18687459]

5. WHO. Towards Universal Access: Scaling Up Priority HIV/AIDS Interventions in the Health Sector. Progress Report 2007. 2007. http://www.who.int/hiv/mediacentre/ universal_access_progress_report_en.pdf

6. Cohen MS, Gay CL. Treatment to prevent transmission of HIV-1. Clin. Infect. Dis. 2010; 50(suppl. 3):S85-S95. [PubMed: 20397961]

7. Gay, CL.; Kashuba, AD.; Cohen, MS. Using antiretrovirals to prevent HIV transmission. In: Mayer, KH.; Pizer, HF., editors. HIV Prevention: A Comprehensive Approach. Elsevier; Amsterdam, The Netherlands: 2009. p. 107-145.Ch. 5

8. Siegfried N, Muller M, Deeks JJ, Volmink J. Male circumcision for prevention of heterosexual acquisition of HIV in men. Cochrane Database Syst Rev. 2009:CD003362. [PubMed: 19370585]

9. Wechsberg WM, Luseno WK. The need for culturally appropriate, gender-specific global HIV prevention efforts with vulnerable women. J. Prev. Interv. Community. 2010; 38:85-88. [PubMed: 20391056]

10. Rerks-Ngarm S, et al. MOPH-TAVEG Investigators. Vaccination with ALVAC and AIDSVAX to prevent HIV-1 infection in Thailand. N. Engl. J. Med. 2009; 361:2209-2220. [PubMed: 19843557]

11. Hendrix CW, Cao YJ, Fuchs EJ. Topical microbicides to prevent HIV: clinical drug development challenges. Annu. Rev. Pharmacol. Toxicol. 2009; 49:349-375. [PubMed: 19006450]

12. Van Damme L, et al. COL-1492 Study Group. Effectiveness of COL-1492, a nonoxynol-9 vaginal gel, on HIV-1 transmission in female sex workers: a randomised controlled trial. Lancet. 2002; 360:971-977. [PubMed: 12383665]

13. García-Lerma JG, Paxton L, Kilmarx PH, Heneine W. Oral pre-exposure prophylaxis for HIV prevention. Trends Pharmacol. Sci. 2010; 31:74-81. [PubMed: 19963288]

14. Denton PW, Garcia JV. Novel humanized murine models for HIV research. Curr. HIV/AIDS Rep. 2009; 6:13-19. [PubMed: 19149992]

15. Abdool Karim Q, et al. CAPRISA 004 Trial Group. Effectiveness and safety of tenofovir gel, an antiretroviral microbicide, for the prevention of HIV infection in women. Science. 2010; 329:1168-1174. [PubMed: 20643915]

16. Parikh UM, et al. Complete protection from repeated vaginal simian-human immunodeficiency virus exposures in macaques by a topical gel containing tenofovir alone or with emtricitabine. J. Virol. 2009; 83:10358-10365. [PubMed: 19656878] 
17. Schwartz, J., et al. Microbicides 2008. New Delhi, India: Feb 24-27. 2008 Preliminary results from a pharmacokinetic study of the candidate vaginal microbicide agent $1 \%$ tenofovir gel [abst B011-610].

18. Cranage M, et al. Prevention of SIV rectal transmission and priming of T cell responses in macaques after local pre-exposure application of tenofovir gel. PLoS Med. 2008; 5:e157. discussion e157. [PubMed: 18684007]

19. Fletcher PS, et al. Ex vivo culture of human colorectal tissue for the evaluation of candidate microbicides. AIDS. 2006; 20:1237-1245. [PubMed: 16816551]

20. Rohan LC, et al. In vitro and ex vivo testing of tenofovir shows it is effective as an HIV-1 microbicide. PLoS ONE. 2010; 5:e9310. [PubMed: 20174579]

21. Borkow G, Barnard J, Nguyen TM, Belmonte A, Wainberg MA, Parniak MA. Chemical barriers to human immunodeficiency virus type 1 (HIV-1) infection: retrovirucidal activity of UC781, a thiocarboxanilide nonnucleoside inhibitor of HIV-1 reverse transcriptase. J. Virol. 1997; 71:30233030. [PubMed: 9060662]

22. Fletcher $P$, et al. The nonnucleoside reverse transcriptase inhibitor UC-781 inhibits human immunodeficiency virus type 1 infection of human cervical tissue and dissemination by migratory cells. J. Virol. 2005; 79:11179-11186. [PubMed: 16103169]

23. Patton DL, et al. Preclinical safety assessments of UC781 anti-human immunodeficiency virus topical microbicide formulations. Antimicrob. Agents Chemother. 2007; 51:1608-1615. [PubMed: 17353240]

24. Das K, et al. Roles of conformational and positional adaptability in structure-based design of TMC125-R165335 (etravirine) and related non-nucleoside reverse transcriptase inhibitors that are highly potent and effective against wild-type and drug-resistant HIV-1 variants. J. Med. Chem. 2004; 47:2550-2560. [PubMed: 15115397]

25. Fletcher $P$, et al. Inhibition of human immunodeficiency virus type 1 infection by the candidate microbicide dapivirine, a nonnucleoside reverse transcriptase inhibitor. Antimicrob. Agents Chemother. 2009; 53:487-495. [PubMed: 19029331]

26. Nuttall JP, Thake DC, Lewis MG, Ferkany JW, Romano JW, Mitchnick MA. Concentrations of dapivirine in the rhesus macaque and rabbit following once daily intravaginal administration of a gel formulation of [14C]dapivirine for 7 days. Antimicrob. Agents Chemother. 2008; 52:909-914. [PubMed: 18086845]

27. Nel A, et al. Safety and pharmacokinetics of dapivirine delivery from matrix and reservoir intravaginal rings to HIV-negative women. J. Acquir. Immune Defic. Syndr. 2009; 51:416-423. [PubMed: 19623693]

28. Nel AM, et al. Safety, tolerability, and systemic absorption of dapivirine vaginal microbicide gel in healthy, HIV-negative women. AIDS. 2009; 23:1531-1538. [PubMed: 19550287]

29. Cohen MS, Gay C, Kashuba AD, Blower S, Paxton L. Narrative review: antiretroviral therapy to prevent the sexual transmission of HIV-1. Ann. Intern. Med. 2007; 146:591-601. [PubMed: 17438318]

30. Dumond JB, et al. Maraviroc concentrates in the cervicovaginal fluid and vaginal tissue of HIVnegative women. J. Acquir. Immune Defic. Syndr. 2009; 51:546-553. [PubMed: 19546811]

31. Brown, K., et al. Antiretrovirals for prevention: maraviroc exposure in the semen and rectal tissue of healthy male volunteers after single and multiple dosing. 17th Conference on Retroviruses and Opportunistic Infections; San Fransisco, CA. 16-19 February 2010;

32. Dumond JB, et al. Antiretroviral drug exposure in the female genital tract: implications for oral pre- and post-exposure prophylaxis. AIDS. 2007; 21:1899-1907. [PubMed: 17721097]

33. Jones, AE.; Talameh, JA.; Patterson, KB.; Rezk, N.; Prince, H.; Kashuba, ADM. First-dose and steady-state pharmacokinetics of raltegravir in the genital tract of hiv negative women. 10th International Workshop on Clinical Pharmacology of HIV Therapy; Amsterdam, The Netherlands. 15-17 April 2009;

34. Salas Herrera IG, Pearson RM, Turner P. Quantitation of albumin and alpha-1-acid glycoprotein in human cervical mucus. Hum. Exp. Toxicol. 1991; 10:137-139. [PubMed: 1675106] 
35. Patterson, KB., et al. Exposure of extracellular and intracellular tenofovir and emtricitabine in mucosal tissues after a single fixed dose of TDF/FTC: implications for pre-exposure HIV prophylaxis (PrEP). XVIII International AIDS Conference; Vienna, Austria. 18-23 July 2010;

36. Veazey RS, Springer MS, Marx PA, Dufour J, Klasse PJ, Moore JP. Protection of macaques from vaginal SHIV challenge by an orally delivered CCR5 inhibitor. Nat. Med. 2005; 11:1293-1294. [PubMed: 16273102]

37. Subbarao S, et al. Chemoprophylaxis with tenofovir disoproxil fumarate provided partial protection against infection with simian human immunodeficiency virus in macaques given multiple virus challenges. J. Infect. Dis. 2006; 194:904-911. [PubMed: 16960777]

38. García-Lerma JG, et al. Prevention of rectal SHIV transmission in macaques by daily or intermittent prophylaxis with emtricitabine and tenofovir. PLoS Med. 2008; 5:e28. [PubMed: 18254653]

39. Denton PW, et al. Antiretroviral pre-exposure prophylaxis prevents vaginal transmission of HIV-1 in humanized BLT mice. PLoS Med. 2008; 5:e16. [PubMed: 18198941]

40. Denton PW, et al. Systemic administration of antiretrovirals prior to exposure prevents rectal and intravenous HIV-1 transmission in humanized BLT mice. PLoS ONE. 2010; 5:e8829. [PubMed: 20098623]

41. García-Lerma JG, et al. Intermittent prophylaxis with oral truvada protects macaques from rectal SHIV infection. Sci. Transl. Med. 2010; 2:14ra4.

42. Tsai CC, et al. Effectiveness of postinoculation ${ }^{\circledR}$-9-(2-phosphonylmethoxypropyl) adenine treatment for prevention of persistent simian immunodeficiency virus SIVmne infection depends critically on timing of initiation and duration of treatment. J. Virol. 1998; 72:4265-4273. [PubMed: 9557716]

43. Cardo DM, et al. A case-control study of HIV seroconversion in health care workers after percutaneous exposure. Centers for Disease Control and Prevention Needlestick Surveillance Group. N. Engl. J. Med. 1997; 337:1485-1490. [PubMed: 9366579]

44. Garnett GP, Anderson RM. Antiviral therapy and the transmission dynamics of HIV-1. J. Antimicrob. Chemother. 1996; 37(suppl. B):135-150. [PubMed: 8818836]

45. Chakraborty H, et al. Viral burden in genital secretions determines male-to-female sexual transmission of HIV-1: a probabilistic empiric model. AIDS. 2001; 15:621-627. [PubMed: 11317000]

46. Bunnell R, et al. Changes in sexual behavior and risk of HIV transmission after antiretroviral therapy and prevention interventions in rural Uganda. AIDS. 2006; 20:85-92. [PubMed: 16327323]

47. Sullivan, P., et al. Reduction of HIV transmission risk and high sex risk while prescribed ART: results from discordant couples in Rwanda and Zambia. 16th Conference on Retroviruses and Opportunistic Infections; Montreal, Canada. 8-11 February 2009;

48. Vourvahis M, et al. The pharmacokinetics and viral activity of tenofovir in the male genital tract. J. Acquir. Immune Defic. Syndr. 2008; 47:329-333. [PubMed: 18197124]

49. Bonora, S., et al. Steady-state raltegravir penetration in seminal plasma of healthy volunteers. 17th Conference on Retroviruses and Opportunistic Infections; San Fransisco, CA. 16-19 February 2010;

50. Taylor, ST., et al. Darunavir concentrations exceed the protein-corrected EC50 for wild type HIV in the semen on HIV-1 men. 17th Conference on Retroviruses and Opportunistic Infections; San Fransisco, CA. 16-19 February 2010;

51. Dumond JB, et al. Differential extracellular and intracellular concentrations of zidovudine and lamivudine in semen and plasma of HIV-1-infected men. J. Acquir. Immune Defic. Syndr. 2008; 48:156-162. [PubMed: 18360288]

52. Diem K, et al. Male genital tract compartmentalization of human immunodeficiency virus type 1 (HIV). AIDS Res. Hum. Retroviruses. 2008; 24:561-571. [PubMed: 18426336]

53. Philpott $S$, et al. Human immunodeficiency virus type 1 genomic RNA sequences in the female genital tract and blood: compartmentalization and intrapatient recombination. J. Virol. 2005; 79:353-363. [PubMed: 15596829] 
54. Wilson DP, Law MG, Grulich AE, Cooper DA, Kaldor JM. Relation between HIV viral load and infectiousness: a model-based analysis. Lancet. 2008; 372:314-320. [PubMed: 18657710]

55. Vödrös D, Fenyö EM. Primate models for human immunodeficiency virus infection. Evolution of receptor use during pathogenesis. Acta Microbiol. Immunol. Hung. 2004; 51:1-29. [PubMed: 15362285]

56. Subbarao S, et al. Direct stringency comparison of two macaque models (single-high vs. repeatlow) for mucosal HIV transmission using an identical anti-HIV chemoprophylaxis intervention. J. Med. Primatol. 2007; 36:238-243. [PubMed: 17669212]

57. Choudhary SK, et al. Suppression of human immunodeficiency virus type 1 (HIV-1) viremia with reverse transcriptase and integrase inhibitors, CD4+ T-cell recovery, and viral rebound upon interruption of therapy in a new model for HIV treatment in the humanized Rag2-/-\{gamma $\}$ c-/mouse. J. Virol. 2009; 83:8254-8258. [PubMed: 19494021]

58. Grivel JC, Margolis L. Use of human tissue explants to study human infectious agents. Nat. Protoc. 2009; 4:256-269. [PubMed: 19197269]

59. Kashuba, AD., et al. Do systemic and genital tract tenofovir concentrations predict HIV serocoversion in the CAPRISA 004 tenofovir gel trial?. XVIII International AIDS Conference; Vienna, Austria. 18-23 July 2010; Abstract TUSS0503 


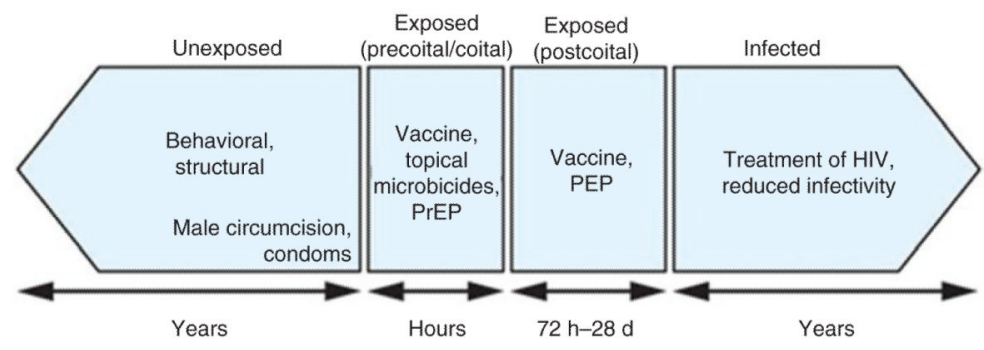

Figure 1.

Opportunities for prevention. PEP, postexposure prophylaxis; PrEP, pre-exposure prophylaxis. 


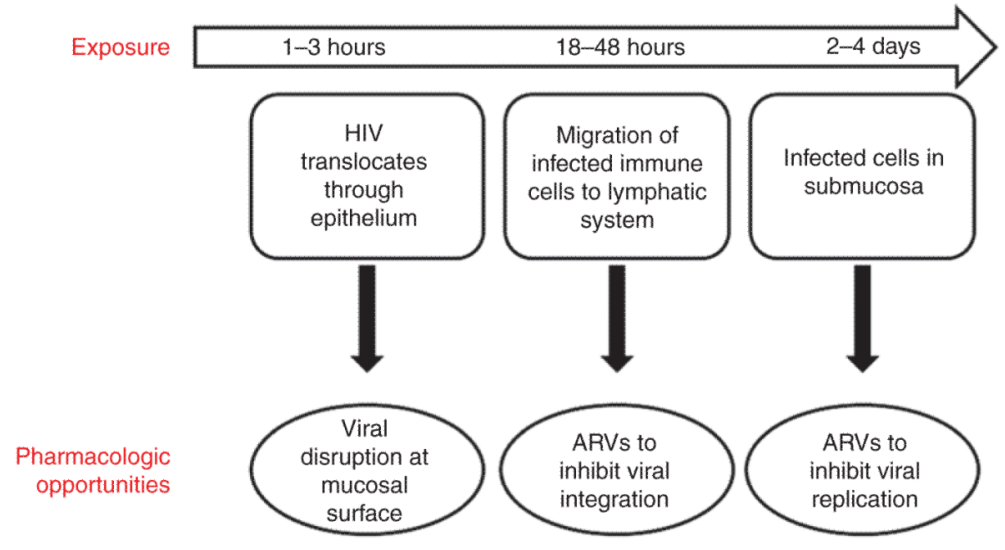

Figure 2.

Timeline of mucosal infection. ARV, antiretroviral. 

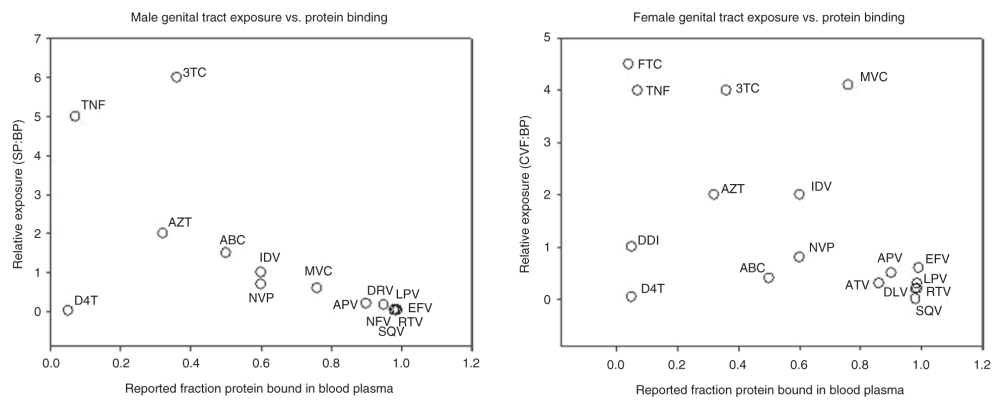

Figure 3.

Relationship of total genital tract exposure to blood plasma protein binding. 3TC, lamivudine; ABC, abacavir; APV, amprenavir; ATV, atazanavir; AZT, zidovudine; D4T, stavudine; DDI, didanosine; DLV, delavirdine; EFV, efavirenz; FTC, emtricitabine; IDV, indinavir; LPV, lopinavir; MVC, maraviroc; NVP, nevirapine; RTV, ritonavir; SQV, saquinavir; TNF, tenofovir. 


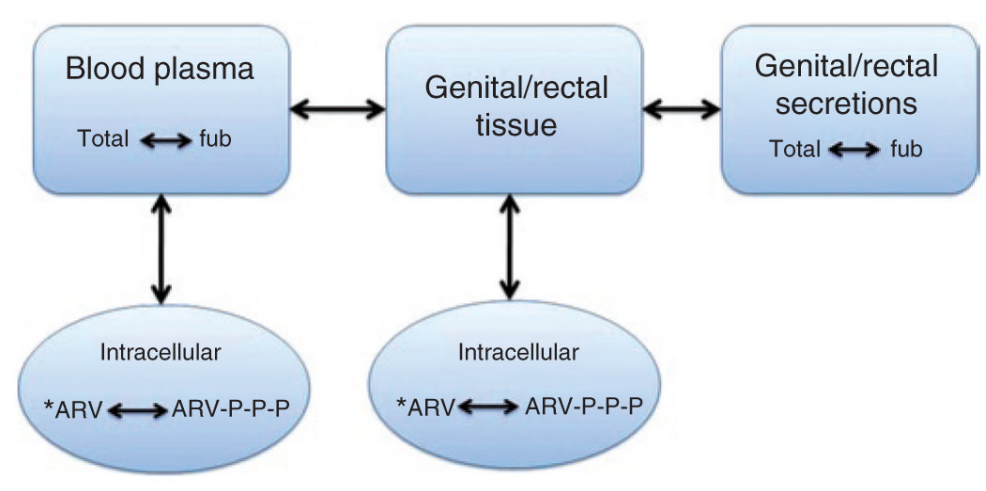

Figure 4.

What should be measured for accurate pharmacokinetic-pharmacodynamic evaluations? *Only nucleoside/tide analog reverse-transcriptase inhibitors require phosphorylation for activation. ARV-P-P-P = tri-phosphorylated metabolite; fub = fraction of drug that is unbound from protein. 


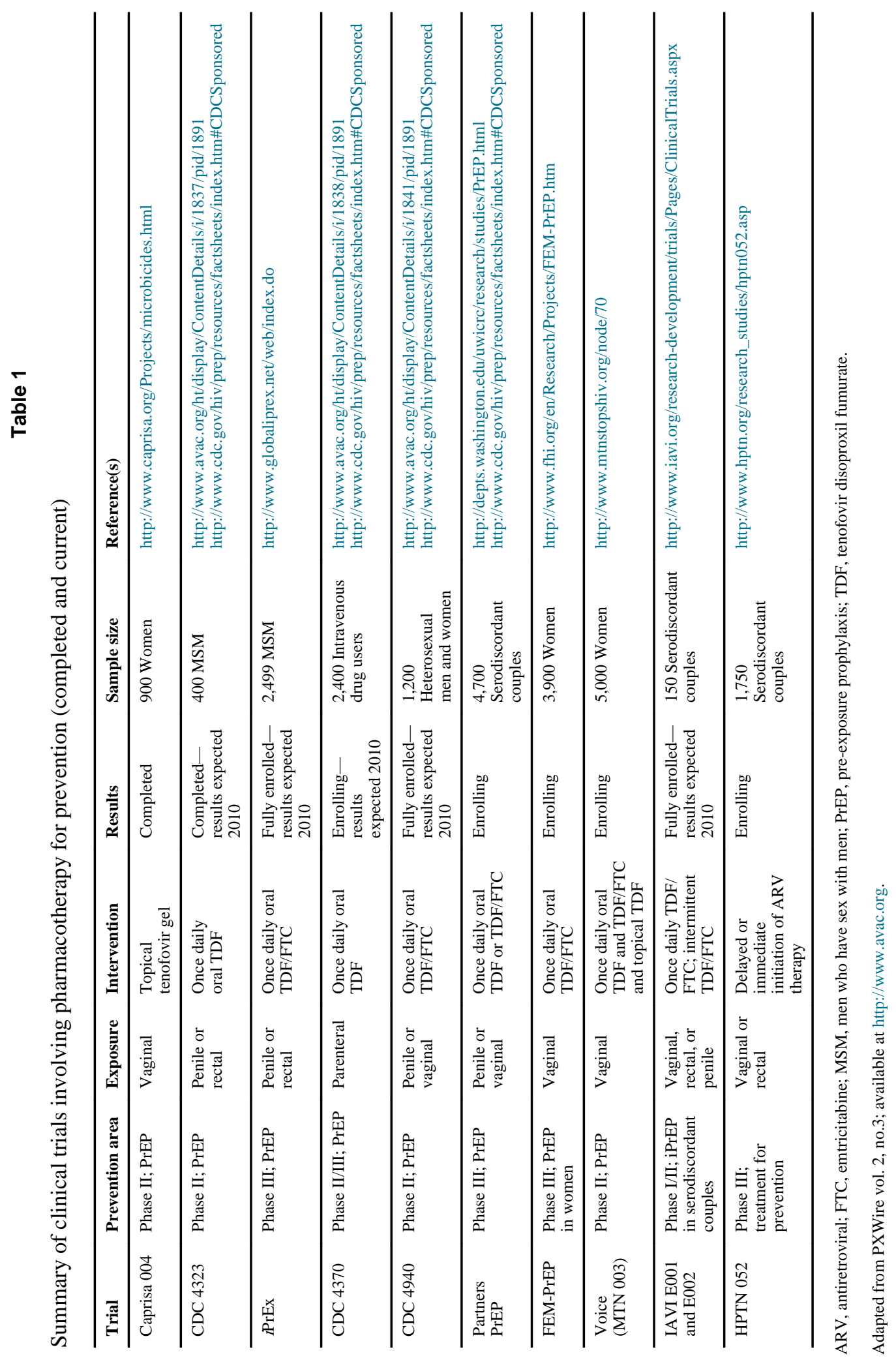


Table 2

Exposures in relevant mucosal fluids and tissues relative to exposure in blood plasma

\begin{tabular}{|c|c|c|c|c|c|}
\hline \multirow[b]{2}{*}{ Drug } & \multicolumn{2}{|c|}{$\begin{array}{c}\text { Female } \\
\text { genital tract }\end{array}$} & \multicolumn{2}{|c|}{$\begin{array}{c}\text { Male } \\
\text { genital tract }\end{array}$} & \multirow{2}{*}{$\begin{array}{c}\begin{array}{c}\text { Rectal } \\
\text { tissue }\end{array} \\
\text { Tissue }\end{array}$} \\
\hline & CVF & Tissue & $\begin{array}{c}\text { Seminal } \\
\text { plasma }\end{array}$ & Intracellular & \\
\hline \multicolumn{6}{|l|}{ NRTIS } \\
\hline Tenofovir & 1.7 & $4.0^{e} / 0.6^{f, g}$ & $4.4(5.1)^{b}$ & $9.4(17.5)^{b}$ & $33^{g}$ \\
\hline Abacavir & 0.7 & 0.4 & 1.5 & & \\
\hline Lamivudine & 16 & 4.0 & 6.0 & 1.0 & \\
\hline Zidovudine & 11 & 1.9 & 2.0 & 0.4 & \\
\hline Didanosine & 2.1 & 1.0 & & & \\
\hline Emtricitabine & 6.2 & ${ }_{42} e, g_{/ 7} f, g$ & 6.0 & ND & $4.4^{g}$ \\
\hline Stavudine & 0.04 & 0.04 & 0.02 & & \\
\hline \multicolumn{6}{|l|}{ PIs } \\
\hline Lopinavir & 0.04 & 0.3 & 0.05 & & \\
\hline Atazanavir & 0.17 & 0.3 & 0.1 & & \\
\hline Ritonavir & 1.1 & 0.2 & 0.03 & & \\
\hline Indinavir & & $1.3^{d}$ & 1 & & \\
\hline Darunavir & & & 0.12 & & \\
\hline Amprenavir & & 0.5 & 0.2 & & \\
\hline Nelfinavir & & & 0.05 & & \\
\hline Saquinavir & & ND & 0.03 & & \\
\hline \multicolumn{6}{|l|}{ NNRTIS } \\
\hline Efavirenz & 0.003 & 0.006 & 0.03 & & \\
\hline Nevirapine & & 0.8 & 0.7 & & \\
\hline Delavirdine & & 0.2 & 0.16 & & \\
\hline \multicolumn{6}{|c|}{ Entry inhibitors } \\
\hline Maraviroc & $1.9(2.7)^{b, c}$ & $(1.9)^{\mathcal{C}}$ & $0.6^{c}$ & & $9(28)^{b, c}$ \\
\hline \multicolumn{6}{|c|}{ Integrase Inhibitors } \\
\hline Raltegravir & 1.0 & & 3.2 & & \\
\hline
\end{tabular}

Comparisons are between tissue/BP-paired samples after a single dose unless otherwise noted.

AUC, area under the concentration-time curve; BP, blood plasma; CVF, cervicovaginal fluid; NNRTI, non-nucleoside analog reverse-transcriptase inhibitor; NRTI, nucleoside/ tide analog reverse-transcriptase inhibitor; PI, protease inhibitor.

$b_{\text {Dose steady-state ratios. }}$

${ }^{c}$ AUC tissue:AUC BP.

$d_{\text {With boost ritonavir. }}$

$e_{\text {Cervical. }}$

$f_{\text {Vaginal. }}$

$g_{\text {AUC tissue0-14 days:AUC BP0-14 days. }}$ 
From refs. 29-33, 48-51. 